\title{
The marsupialization of a voluminous dentiger odontogenic keratocyst
}

\author{
Marsupializarea keratochisturilor odontogene dentigere mari - studiu de caz
}

\author{
Cristian Niky Cumpătă', Ruxandra Nicolette Voinea Georgescu, Mihaela Răescu', \\ Mircea Gheorghiță2, Andreea Gabriela Nicola' ${ }^{2}$ Dana Cosac ${ }^{1}$ \\ ${ }^{1}$ Facultatea de Medicină Dentară, Universitatea „Titu Maiorescu“, Bucureşti, România \\ ${ }^{2}$ Facultatea de Medicină Dentară, Universitatea de Medicină şi Farmacie din Craiova, România
}

\begin{abstract}
In 2005, the World Health Organization published the latest classification of odontogenic tumors (1). Within this classification, the odontogenic keratocyst with parakeratosis was called the odontogenickeratocystic tumor and was defined as a "uni- or multilocularintraosseous tumor of odontogenic origin, characteristically lined with a parakatinized type epithelial epithelium with an aggressive potential (1).

The treatment of the dentigerodontogenic keratocyst is surgical and consists mostly of cystectomy (5). For large sizes, marginal or segmental marsupialisation or even resection $(14,15)$ is indicated.

This article presents a clinical case of a voluminous dentigerodontogenickeratocyst, localized to the mandible that was treated by marsupialization because of the risk of damage to the alveolar vasculo-nervous pack as well as the risk of fracture in the pathological bone if the radical treatment of first intention. After decompression of the cyst, the premise of bone regeneration is created due to the absence of intracystic pressure. One year after marsupialization, we proceed with a radical cure of the cyst and once the bone is healed, the edentation is treated by implanto-prosthetic rehabilitation.
\end{abstract}

Keywords: keratocyst, marsupialization, obturator

\section{REZUMAT}

În 2005, Organizaţia Mondială a Sănătăţii a publicat cea mai recentă clasificarea a tumorilor odontogene (1). În cadrul acestei clasificări, keratochistul odontogen cu parakeratoză a fost denumit tumoră keratochistică odontogenă şi a fost definit ca fiind „tumoră intraosoasă uni- sau multichistică de origine odontogenă, fiind caracteristic căptuşită cu un epiteliu scuamos stratificat de tip parakeratinizat şi cu un potenţial agresiv" (1). Tratamentul keratochistului odontogen dentiger este chirurgical şi constă de cele mai multe ori în chistectomie (5). Pentru formele de mari dimensiuni, se indică marsupializarea sau chiar rezecţia marginală sau segmentară

Acest articol prezintă un caz clinic de keratochist odontogen dentiger voluminos, localizat la mandibulă, care a fost tratat prin marsupializare, deoarece prezenta riscul de lezare a pachetului vasculo-nervos alveolar, cât şi riscul de fractură în os patologic dacă s-ar fi tentat tratamentul radical de primă intenţie. După decomprima-rea chistului, se creează premisele unei regenerări osoase, datorată absenţei presiunii intrachistice. La 1 an de la marsupializare se realizează cura radicală a chistului şi după vindecarea osoasă se tratează edentaţia prin reabilitare implanto-protetică.

Cuvinte cheie: keratochist, marsupializare, obturator

\section{INTRODUCERE}

Termenul de keratochist a fost introdus de Plilipsen in 1956 şi a avut la bază aspectul histopatologic al membranei care prezintă cheratinizarea epiteliului. În clasificarea OMS din 1972 se preferă termenul de chist primordial, considerat ca rezultat din degenerarea chistică a epiteliului adamantin, înaintea dezvoltării structurilor dure dentare. Reclasificarea ca un neoplasm real de origine odontogenică subliniază comportamentul agresiv cunoscut, cu o înaltă rată de recidivă (2). Modificările în controlul ciclului celular şi compoziţia locală a matricei extracelulare sunt responsabile pentru acest 
comportament invaziv la nivel local $(8,9)$. Chisturile odontogene ale maxilarelor nu au caracter infiltrativ, ci îşi măresc volumul din cauza creşterii presiunii lichidului osmotic intraluminal (11).

Keratochisturile reprezintă aproximativ 5-10\% din totalul chisturilor odontogene. Apar cel mai frecvent la adolescenţi şi tineri, fiind mai frecvente la sexul masculin (5). Pot fi prezente şi la copii în contextul sindromului nevic bazocelular (Gorlin), caz în care sunt întâlnite keratochisturi multiple, însoţite de leziuni tegumentare, oculare, leziuni ale sistemului nervos şi endocrin. Cel mai frecvent apar la mandibulă în dreptul unghiului mandibular, iar la maxilar în regiunea molară şi canină (5).

Evoluează de obicei asimptomatic, induc resorbţia rădăcinilor şi mobilitatea dinţilor vecini. Au tendinţa de extindere, ducând la liza corticalelor osoase, împing pachetul vasculo-nervos alveolar fără a produce tulburări de sensibilitate $(5,8,12)$.

Radiologic apar ca leziuni osoase radiotransparente, cu limite precise, uni- sau multiloculare. Dacă este însoţită de prezenţa unui dinte intralezio- nal putem vorbi de keratochist odontogen dentiger. Lipsa dintelui inclus sugerează un diagnostic de keratochist odontogen primordial (5).

$\mathrm{Ca}$ tratament, chistectomia este prima intenţie curativă. Marsupializarea este indicată în cazul keratokisturilor dentigere, lăsând posibilitatea erupţiei dintelui inclus, dar şi atunci când dimensiunea leziunii este mare existând riscul de fractură în os patologic. Este de asemenea indicată marsupializarea şi în cazurile de edentaţie mixtă pentru evitarea riscului de lezare al mugurilor dentari, dar şi în cazul chisturilor infectate (6).

\section{MATERIAL ŞI METODĂ}

Pacient în vârstă de 31 ani, clinic sănătos, se prezintă pentru o deformare a regiunii geniene inferioare şi angulo-mandibulare drepte. Leziunea este nedureroasă spontan sau la palpare, tegumente acoperitoare de aspect normal, la palpare se percepe osul cortical deformat. La examenul oral se observă deformarea voluminoasă a corticalei vestibulare şi
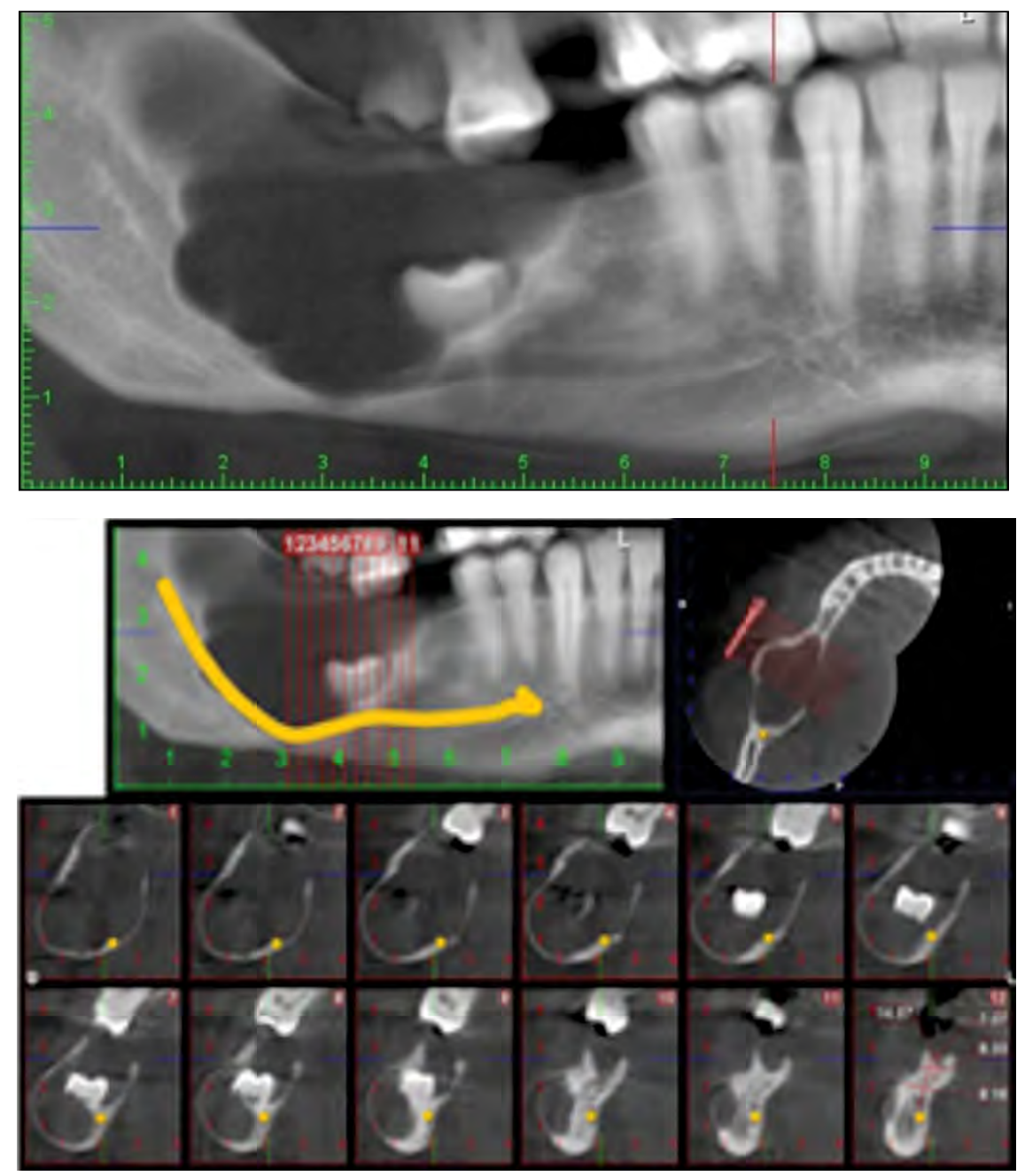

FIGURA 1. Deformarea şi resorbția osoasă severă ale celor două corticale. Pachetul vasculo-nervos alveolar împins mult către bazilară 
orale în regiunea corpului şi unghiului mandibular drept, cu lipsa de pe arcadă a molarilor 1,2 şi 3, mucoasa acoperitoare de aspect normal, nedureroasă spontan sau la palpare, de consistenţă variabilă, alternând zone dure cu zone depresibile în special la nivelul crestei alveolare edentate. Pacientul nu acuză tulburări de sensibilitate în teritoriul nervului alveolar inferior. Dinţii 4.6 şi 4.7 au fost extraşi cu aproximativ 5 ani în urmă (afirmativ).

Pacientul nu a relatat nici un episod dureros în ultimii 5 ani, deformarea corticală fiind lentă, nedureroasă, progresivă, fără modificarea aspectului ţesuturilor adiacente.

Examenul CBCT a evidenţiat o leziune chistică voluminoasă situată la nivelul corpului şi unghiul mandibular drept de 51/42/35 mm, cu dintele 4.8 intrachistic, împingerea pachetului vasculo-nervos alveolar mult spre bazilara mandibulei, cele două corticale vestibulară şi orală foarte resorbite, cu erodarea în totalitate a corticalei crestei alveolare în zona molară pe o suprafaţă de 15/11 mm (Fig. 1).

De asemenea, este erodată şi corticala linguală în suprafaţă de $6 / 8 \mathrm{~mm}$. Dinţii vecini nu sunt interesaţi de leziune.

Se practică o biopsie incizională pentru stabilirea diagnosticului de certitudine. Fragmentul de membrană chistică este recoltat din zona molară acrestei alveolare. Rezultatul examenului histopatologic - membrană conjunctivă căptuşită cu epiteliu pavimentos stratificat, pe suprafaţa căruia se găseşte un strat parakeratinizat - keratochist odontogen dentiger.

\section{PROTOCOL OPERATOR}

În baza rezultatului examenului histopatologic, tratamentul de elecţie este chirurgical - chistectomia cu extracţia dintelui inclus. Având în vedere volumul mare al chistului, resorbţia severă a celor două corticale osoase şi contactul membrane chistice cu pachetul vasculo-nervos alveolar, se decide marsupializarea keratochistului odontogen dentiger împreună cu extracţia dintelui inclus.

Intervenţia se realizează sub anestezie loco-regională. Se excizează o porţiune de 20/15 mm din membrana chistului la nivelul crestei alveolare din regiunea molară, se extrage dintele inclus prin orificiul creat şi se suturează membrana chistică la mucoasa gingivală. Cavitatea chistică se transfor- mă într-o cavitate anexă a cavităţii bucale. Se aplică o meşă iodoformată în defect. După 5 zile se amprentează defectul şi se realizează un obturator din material siliconic. Proteza obturator se adaptează prin micşorarea volumului timp de 1 an la interval de 2 luni. La 1 an de la marsupializare se realizează chistectomia - tehnica în 2 faze. La 2,5 ani de la marsupializare se inseră în regiunea molară două implanturi în poziţiile 4.6 şi 4.7 , care se încarcă provizoriu la 5 luni şi definitiv la 7 luni.

\section{REZULTATE ŞI DISCUȚII}

Având în vedere rezultatul examenului histopatologic de keratochist odontogen cu prezenţa dintelui inclus intralezional, diagnosticul este de keratochist odontogen dentiger $(3,4,5,7,10)$.

Marsupializarea reprezintă o metodă de creare a unei comunicări între chist şi cavitatea orală, prin desfiinţarea unui perete al cavităţii chistice şi deci transformarea acesteia într-o ,cavitate anexă“ a cavităţii orale, marginile membranei chistice fiind suturate la mucoasa orală adiacentă pentru a nu permite închiderea spontană a comunicării oro-chistice $(6,14,15)$.

Indicaţiile marsupializării ca intervenţie tranzitorie sau definitivă sunt reduse: în chisturile supurate, când colecţia este în tensiune, chisturi voluminoase mandibulare cu risc de fractură în os patologic, chisturi dentigere care au raporturi cu numeroşi muguri dentari sau dinţi în erupţie la copii, peretele chistic este singura barieră între chist şi sinus sau nas, starea generală a pacientului nu permite cura radicală sau refuzul pacientului pentru chistectomie $(9,13,11)$.

Metoda are însă avantaje de necontestat: datorită faptului că nu mai există presiune intrachistică, se reduce progresiv volumul chistului, făcând loc regenerării osoase.

Astfel se explică de ce la 1 an de la marsupializare cantitatea de os cortical şi-a dublat volumul, pachetul vasculo-nervos alveolar are tendinţa de revenire la poziţia iniţială (Fig. 2).

Pe măsură ce ţesuturile din profunzime proliferează, se creează premisele regenerării osoase, iar oburatorul siliconic va fi redus fără a fi prejudiciată însă stabilitatea acestuia. Obturatorul şi cavitatea trebuie igienizate zilnic, pentru prevenirea complicaţiilor septice şi a zonelor de iritaţie (Fig. 3). 

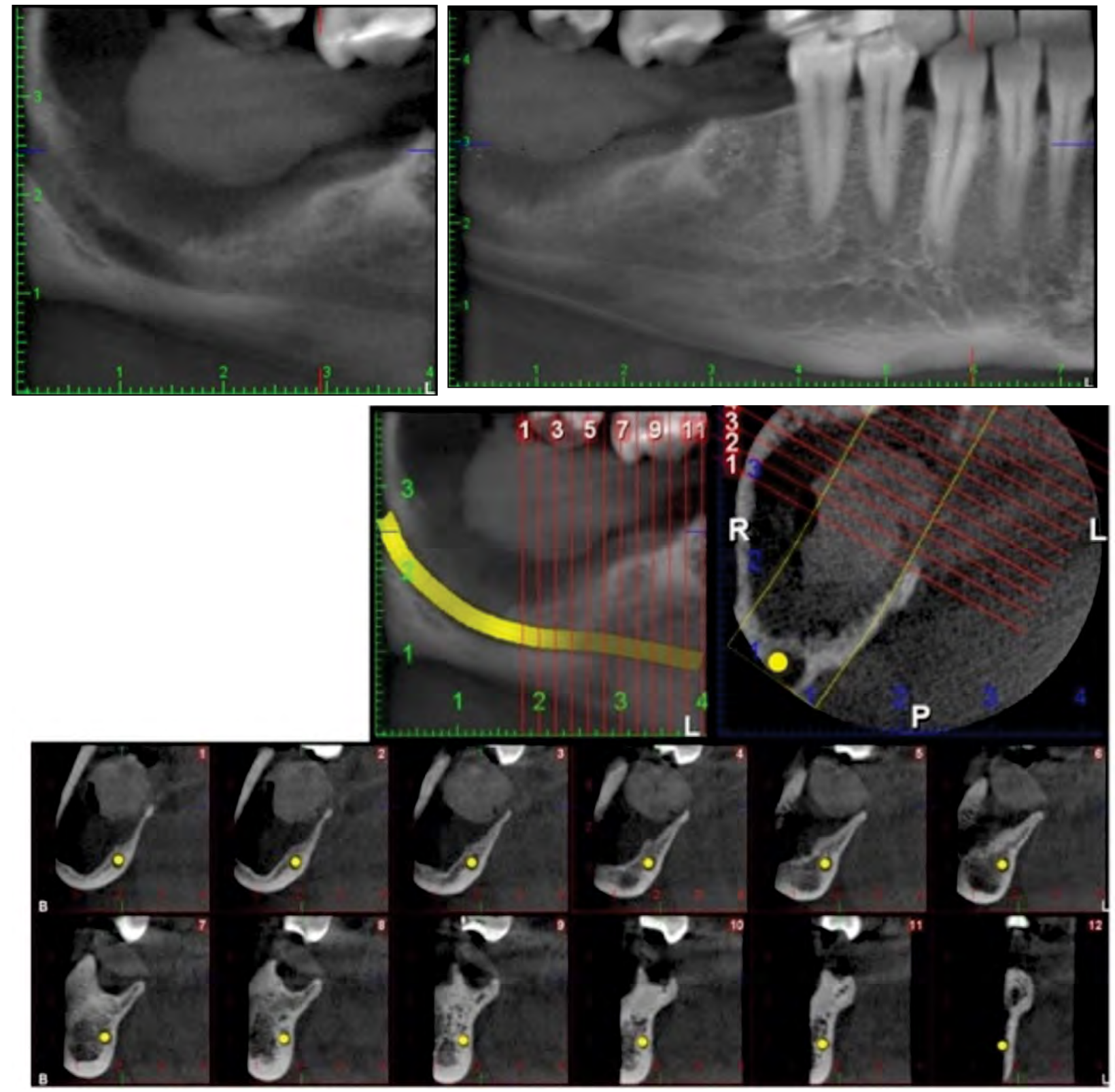

FIGURA 2. Control radiologic la 1 an de la marsupializare - îngroşarea celor două corticale, pachetul vasculo-nervos poziționat mai cranial. Se observă obturatorul siliconic.

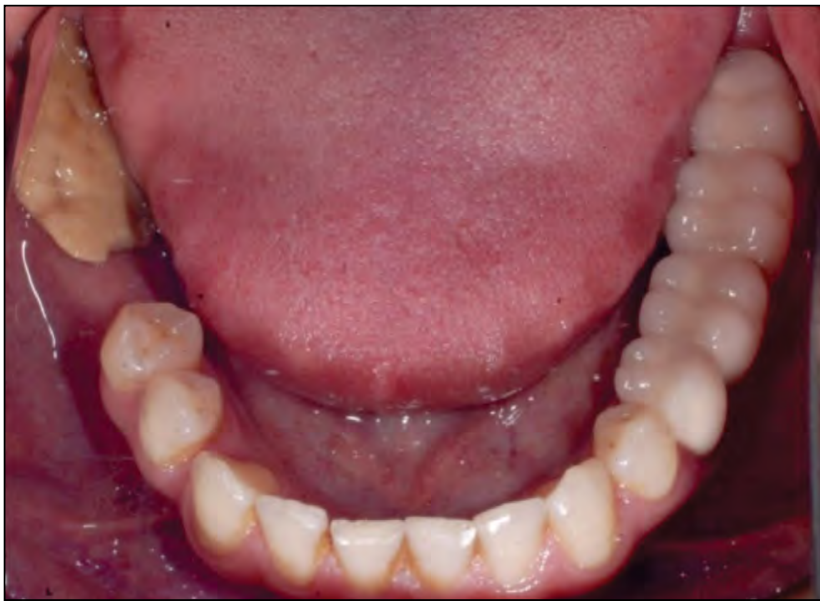

FIGURA 3. Oburatorul siliconic aplicat în cavitatea orală la 1 an de la marsupializare
Metoda are şi dezavantaje: păstrarea unei porţiuni din membrana chistului - poate degenera ameloblastic sau malign, se poate reface dacă nu se menţine deschiderea, vindecare şi cicatrizare completă extrem de lentă. Cu toate aceste inconveniente, sunt autori care preferă ca după chistectomie să marsupializeze cavitatea în cazul chisturilor voluminoase, când dehiscenţa este previzibilă şi implicit infectarea plăgii postoperatorii.

La 2 ani de la marsupializare volumul osos este la 2/3 din volumul iniţial, iar pachetul vasculo-nervos alveolar aproape a revenit la poziţia iniţială (Fig. 4).

După 2,5 de la marsupializare se inseră implanturi dentare în poziţiile 4.6 şi 4.7. Controlate radio- 

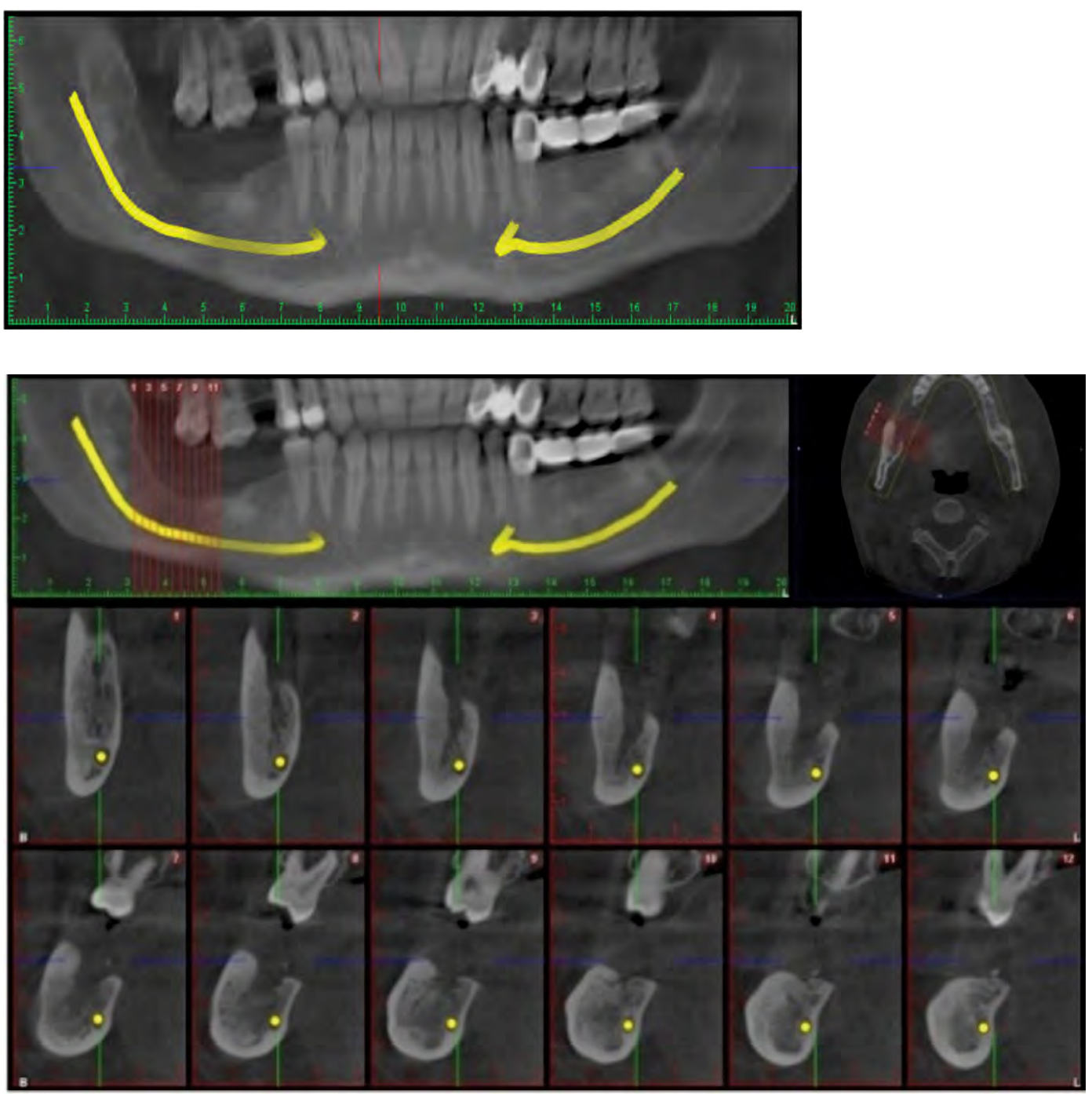

FIGURA 4. Refacerea volumului osos la 2/3 din volumul inițial, canalul mandibular în poziție cranială

logic la 3 ani, implanturile se încarcă provizoriu şi apoi definitiv. Radiografia făcută la 3 ani de la marsupializare găseşte osul refăcut în proporţie de $90 \%$ şi pachetul vasculo-nervos mentonier în poziţie anatomică (Fig. 5).

\section{CONCLUZII}

Marsupializarea ca metodă de tratament a fost considerată o bună bucată de vreme ca paliativă, eventual ca prim timp în vederea efectuării ulteri-
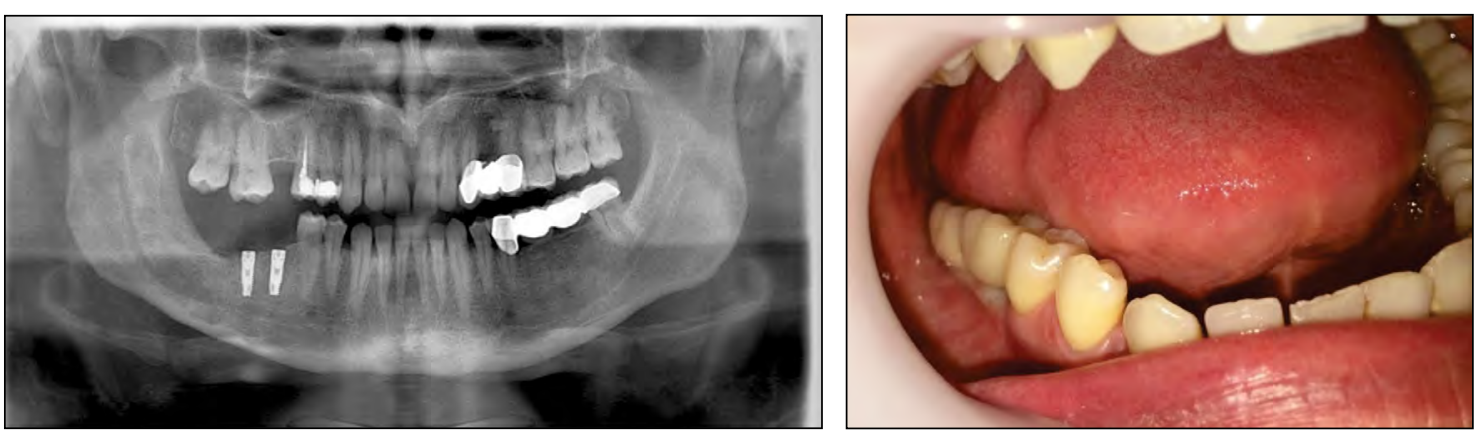

FIGURA 5. La 3 ani de la marsupializare volumul osos refăcut în proporție de 90\% cu canalul mandibular în poziție anatomică 
oare a unei cure radicale. Experienţa a arătat însă că uneori în chisturile mari, cum este cazul de faţă, este preferabilă marsupializarea înaintea curei radicale.

De asemenea, în cazurile în care s-a practicat cura radicală, când postoperator se produce o de- hiscenţă, în mod obligatoriu trebuie să se recurgă la marsupializare (6).

\section{Menţiune}

Toţi autorii au contribuţie egală în realizarea acestui articol.

\section{BIBLIOGRAFIE}

1. Barnes L, Eveson J, Reichart P, Sidransky D. Pathology and genetics of tumours of the head and neck. World Health Organization classification tumours: 283-327.2005

2. Bhargava D, Deshpande A, Pogrel MA. Keratocystic odontogenic tumour (KCOT)-a cyst to a tumour. Oral Maxillofac Surg 16(2): 163-170, 2012

3. Brannon RB. The odontogenic keratocyst. A clinicopathologic study of 312 cases. Part II. Histologic features. Oral Surg Oral Med Oral Pathol 43(2): 233-255.1977

4. Browne R.The pathogenesis of odontogenic cysts: a review, J Oral Pathol Med 4(1):31-46,1975

5. Bucur A. Compendiu de chirurgie oro-maxilo-facială. Vol II 452-453, 2009

6. Burlibasa C. Chirurgie orală şi maxilofacială. Editura medicală, 715-715, 726-727, 1999

7. Dejaco D, Url C, Schartinger V, Haug A, Fischer N, Riedl D et al. Approximation of head and neck cancer volumes in contrast enhanced CT. Canc Imag15(1):16,2015

8. Li TJ, Browne RM, Matthews JB. Immunocytochemical expression of parathyroidhormone related protein (PTHrP) in odontogenicjaw cysts, B rJ Oral MaxillofacSurg 35(4): 275-279, 1997

9. Madras J, Lapointe H. Keratocystic odontogenic tumour: reclassification of theodontogenic keratocyst from cyst to tumour. J Can Dent Assoc 74(2): 165, 2008

10. Manor E Kachko L Puterman MB, Szabo G, Bodner L. Cystic lesions of thejaws - a clinicopathological study of 322 cases and review of the literature. Int J Med Sci9(1)| 20-26, 2012

11. Maurette PE, Jorge J, de Moraes M. Consen/ative treatment protocol of odontogenic keratocyst: a preliminary study. J Oral Maxillofac Surg 64(3): 379-383, 2006

12. Menon S. Keratocyst odontogenic tumors:etiology, pathogenesis and treatment revisited. J Maxillofac Oral Surg 14(3): 541-547, 2015

13. Miloro M, Ghali G, Larsen P. Waite P. Peterson's principles of oral and maxillofacial surgery, 2nd ed. PMPH»USA, 563-722. 2004

14. Pitak-Arnnop P, Chaine A, Oprean N, Dhanuthai K, Bertrand jC, Bertolus $C$. Management of odontogenic keratocysts of the jaws: a ten-year experience with 120 consecutive lesions.) Cranioniaxillofac Surg 38(5): 358-364, 2010

15. Pitak-Arnnop P, Dhanulhai Hemprich A. Pausch NC. Follicular cysts, odontogenickeratocyst and gorlinn goltz syndrome: some clinicopathologic aspects. J Craniofac Surg 22(3):1170, 2011 